\title{
Generación de Modelos de Elevación Digital (DEM) a partir del análisis fotogramétrico utilizando imágenes CARTA-2005
}

\section{Generation of Digital Elevation Models (DEM) by means of Photogrammetric Techniques using CARTA-2005 Imagery}

Maikel Méndez-Morales'

Daniela Jiménez-Monge²

Fecha de recepción: 20 de enero del 2012

Fecha de aprobación: 19 de marzo del 2012

Méndez, M; Jiménez, D. Generación de Modelos de Elevación Digital (DEM) a partir del análisis fotogramétrico utilizando imágenes CARTA-2005. Tecnología en Marcha. Vol. 26, N 4. Pág 26-35

I Profesor Investigador, Centro de Investigaciones en Vivienda y Construcción (CIVCO) del Instituto Tecnológico de Costa Rica. Apdo. 159-7050. Tel. (506) 2550-2425. Fax (506) 255I-6663. Correo electrónico: mamendez@itcr.ac.cr

2 Consultora. Ingeniería en Construcción. Instituto Tecnológico de Costa Rica. Apdo. I59-7050. Tel. (506) 2550-2425. Fax (506) 255 I-6663. Correo electrónico: danielajimenezm@gmail.com 
Palabras clave

CARTA-2005; DEM; ERDAS-LPS; fotogrametría; GCP.

\section{Resumen}

Se utilizaron las fotografías aéreas de la Misión Carta-2005 en la generación de Modelos de Elevación Digital (DEM, por sus siglas en inglés) para un área de estudio de $180 \mathrm{~km}^{2}$, situada al noroeste de la ciudad de Cartago, Costa Rica. Las resoluciones espaciales probadas fueron de 2,5 y $10 \mathrm{~m}$. Se usó un total de 42 Puntos de Control del Terreno (GCP, por sus siglas en inglés) para establecer la orientación externa del bloque estereoscópico. Se seleccionó ERDAS Imagine-LPS como la estación fotogramétrica de análisis. En las imágenes de CARTA-2005 se detectaron varias deficiencias, incluyendo baja calidad del escaneo digital y el contraste radiológico. Los resultados muestran que luego de aplicar compensación radiológica y filtros vectoriales, se pueden generar DEM de calidad satisfactoria a partir de estas imágenes. El Error cuadrático medio (RMSE, por sus siglas en inglés) se mantuvo por debajo del pixel, independientemente de la resolución espacial. Las imágenes CARTA2005, aun cuando deben utilizarse con precaución, representan una fuente valiosa de información espacial para el territorio costarricense.

\section{Key words}

CARTA-2005; DEM; ERDAS-LPS; GCP; Photogrammetry

\begin{abstract}
The CARTA-2005 mission aerial photographs were used to generate Digital Elevation Models (DEMs) for a $180 \mathrm{~km}^{2}$ study area located northwest of the city of Cartago, Costa Rica. Tested spatial resolutions included 2, 5 and $10 \mathrm{~m}$. A total of 42 Ground Control Points (GCPs) were used to establish the exterior orientation of the stereo block. ERDAS Imagine-LPS was selected as Photogrammetric Workstation. Various deficiencies were detected within the CARTA-2005 images, included poor scanning and radiometric contrast. Results show that after applying radiologic compensation and vector filters, satisfactory DEMs can be generated by means of these images. RMSE were below the pixel size regardless of the selected spatial resolution. CARTA-2005 must be used with care but it represents a valuable source of spatial information for the Costa Rican territory.
\end{abstract}

\section{Introducción}

Los modelos de elevación digital (DEM, por sus siglas en inglés) son productos estándar del análisis fotogramétrico digital de fotografías aéreas o imágenes satelitales (Miller \& Small, 2003). La aplicación de los DEM se extiende a campos tan diversos como la geografía, la hidrología, la ecología, los estudios de impacto ambiental y la cartografía en general (Wu et at., 2008).

La fotogrametría digital utiliza técnicas de comparación de imágenes para estimar la elevación de los objetos en el campo a partir de pares estereoscópicos. Posteriormente, la creación de los DEM se concentra en procesos automáticos que maximizan los recursos computacionales disponibles hoy en día. La calidad de los DEM elaborados a partir de pares estereoscópicos se ve afectada por la topografía del terreno y la calidad de la información base, ya sean imágenes satelitales o fotografía aérea. Otras variables, tales como la resolución espacial de los datos fuente, los algoritmos del software fotogramétrico y la estructura seleccionada (raster versus red triangular irregular), también juegan un papel importante en la calidad del producto final (Leica Geosystems, 20I0). Los DEM de alta resolución son cada más necesarios en aplicaciones específicas como la definición de redes de drenaje a nivel urbano, pero rara vez se encuentran disponibles, razón por la cual deben ser generados (Hunter et al., 2007, Méndez, 20 I2).

La generación de DEM a partir de la fotografía aérea tiene ventajas, ya que el vuelo se puede planear con anticipación para satisfacer las necesidades del cliente, se puede variar la resolución espacial de los datos a partir de la altitud del vuelo y pueden 
desplegarse casi en cualquier momento si las condiciones del clima lo permiten.

Sin embargo, también existen inconvenientes, dado que se requiere una red suficientemente robusta de Puntos de Control del Terreno (GCP, por sus siglas en inglés) que se traslapen en la mayor cantidad de fotografías posible. Entre menor sea la altura de vuelo, mayor será la resolución de los datos pero mayor será la cantidad de GCP necesarios. Otro inconveniente de los vuelos aerotransportados tiene que ver con los diferentes grados y ángulos de iluminación que se den durante el vuelo, el cual puede durar días o incluso meses. Esto hace que se produzcan diferencias radiológicas en las imágenes, dadas las diferentes fechas de adquisición, que resultan difíciles de compensar en el proceso de análisis fotogramétrico (Baltsavias \& Stallmann, 1993). Como consecuencia de esto, muchas veces se

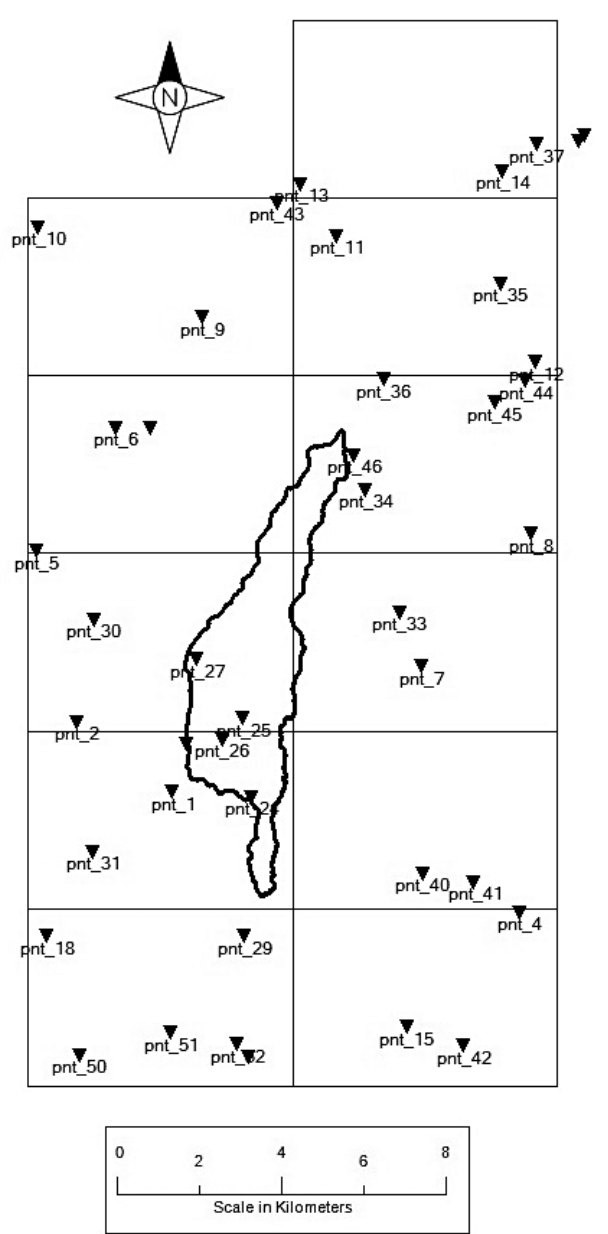

Figura I. Delimitación del área de trabajo junto con la ubicación de los GCP. generan zonas de "redundancia" de información o datos que resultan irrelevantes. Se han aplicado diversos filtros en software de análisis con el propósito de limitar esta situación.

El propósito de este estudio es generar DEM con diversas resoluciones espaciales a partir de fotografías aéreas tomadas por el vuelo CARTA-2005, al mismo tiempo que son evaluados cualitativa y cuantitativamente. La aplicación última de estos DEM se centra en el estudio de fenómenos de inundación a nivel urbano en el sector noroeste de la ciudad de Cartago, Costa Rica.

\section{Metodología}

\section{Área de estudio}

El área de estudio se encuentra al noroeste de la provincia de Cartago, Costa Rica, y abarca la zona de drenaje correspondiente a la cuenca del río Toyogres. El área total contemplada es de aproximadamente de $180 \mathrm{~km}^{2}$ (figura I). El cambio de elevación es abrupto, pasando desde los 3405 msnm hasta los 1055 msnm.

\section{Metadatos}

La fuente de información utilizada en la generación de los diversos DEM se centró en las fotografías aéreas tomadas durante la misión CARTA-2005, a petición de la Unidad Ejecutora del Catastro Nacional de Costa Rica. El vuelo, de tipo analógico, produjo fotografías a color a escala 1:25.000, utilizando una cámara Wild-RC30 de Leica con una distancia focal nominal de $305 \mathrm{~mm}$ y calibrada en noviembre de 2004. Las imágenes resultantes se escanearon en el Centro Nacional de Alta Tecnología (CENAT) y exportadas a formato GEOTIFF.

\section{Parámetros cartográficos}

El sistema de proyección cartográfica utilizado en este estudio corresponde al Costa Rica Transversal de Mercator, CRTM05 (cuadro I), definido por la Unidad Ejecutora del Catastro Nacional de Costa Rica (IGN 2008). Para la referencia vertical de los puntos se tienen en cuenta las diferencias verticales de los puntos o elevaciones elipsoidales sobre el sistema GPS obtenidas de los ajustes de observaciones sobre el elipsoide WGS-84. A las elevaciones elipsoidales se les aplicó el modelo regional de ondulación CARIB-97, obteniendo así las elevaciones ortométricas. 
Cuadro I. Características del sistema de proyección CRTM05.

\begin{tabular}{|c|c|}
\hline Sistema Proyección & CRTM05 \\
\hline Esferoide & WGS84 \\
\hline Datum & WGS85 \\
\hline Meridiano central & -84 \\
\hline Latitud de referencia & 0 \\
\hline Falso Este & 500000 \\
\hline Falso Norte & 0 \\
\hline Factor de escala & 0.9999 \\
\hline
\end{tabular}

\section{Orientación externa}

Se utilizó un total de 42 GCP para respaldar la orientación externa de las fotografías aéreas CARTA-2005 (figura I y cuadro 2). El objetivo primordial de los GCP es establecer la relación entre el sistema de coordenadas de la proyección cartográfica (CRTM05) y el sistema de coordenadas de las imágenes (a nivel de pixel). De ese total, 23 puntos se referían al estudio realizado por la empresa BLOM para el Plan Regional Urbano de la Gran Área Metropolitana (PRUGAM) (PRUGAM, 2008), mientras que los restantes 19 puntos fueron tomados por personeros del Instituto Tecnológico de Costa Rica (ITCR). En ambos casos se utilizaron dispositivos GPS diferenciales de la marca Trimble, modelos 5700 y R3 respectivamente.

Los protocolos de toma de datos utilizados se apegaron a las recomendaciones del fabricante, de manera tal que los GCP se levantaron en localidades claramente identificables.

La figura 2 muestra la ubicación en el campo (croquis) y en las fotografías aéreas CARTA-2005 para dos diferentes GCP, el 084 (PRUGAM) y el 013 (ITCR). Cada toma de datos contó con una exposición del al menos 30 minutos y se procesaron mediante el software TRIMBLE Business Center. Cada GCP representa un punto de control total ( $X, Y$ y $Z$ ) y cuenta con su respectivo informe que respalda la calidad de cada punto. La selección de los puntos tomados por el ITCR se hizo pensando en la mayor cantidad de puntos por fotografía aérea. Con estos equipos se consiguieron precisiones de $3 \mathrm{~mm}+0.5 \mathrm{ppm}$. (emc) en levantamiento estático, modalidad utilizada en todos los puntos.

\section{Aerotriangulación Analítica Digital (AAD)}

En el proceso de Aerotriangulación Analítica Digital (AAD) se busca asociar física y matemáticamente las imágenes individuales disponibles y atarlas a un bloque único, utilizando como referencia los datums horizontales y verticales de referencia. El software utilizado para este estudio fue ERDAS Imagine-LPS de Leica Photogrammetric, versión 201 I . El modelo matemático utilizado fue el de funciones racionales (RPC), el cual establece una correlación entre los pixeles de la imagen y su posición en el terreno a partir del principio del parallax (Leica Geosystems, 2010).

Las diferencias medidas con base en el parallax en un esquema pixel-pixel en imágenes estereoscópicas son convertidas a elevaciones absolutas, utilizando funciones trigonométricas y la información de orientación interna del sensor, ya sea la cámara aérea o los sensores satelitales. ERDAS-LPS utiliza un algoritmo único de correlación automática que

Cuadro 2. GCP para el área de estudio.

\begin{tabular}{|c|c|c|c|c|c|}
\hline Punto & ID & Este (m) & Norte (m) & $\begin{array}{c}\text { Elevación } \\
\text { ortométrica }(m)\end{array}$ & Fuente \\
\hline 1 & 84 & 508468.227 & 1089728.375 & 1408.314 & PRUGAM \\
\hline 2 & 83 & 506474.039 & 1091174.132 & 1422.685 & PRUGAM \\
\hline 3 & 81 & 500408.336 & 1094427.504 & 1282.972 & PRUGAM \\
\hline 4 & 75 & 515662.109 & 1087226.358 & 1287.209 & PRUGAM \\
\hline 5 & 74 & 505659.410 & 1094723.547 & 1546.611 & PRUGAM \\
\hline 6 & 60 & 507287.589 & 1097276.739 & 1947.864 & PRUGAM \\
\hline 7 & 61 & 513629.784 & 1092319.247 & 1625.719 & PRUGAM \\
\hline 8 & 45 & 515912.320 & 1095086.045 & 1961.431 & PRUGAM \\
\hline 9 & 44 & 509082.544 & 1099571.126 & 2302.552 & PRUGAM \\
\hline 10 & 43 & 505689.041 & 1101444.937 & 2051.836 & PRUGAM \\
\hline 11 & 30 & 511865.323 & 1101252.101 & 2750.681 & PRUGAM \\
\hline 12 & 31 & 516010.364 & 1098642.627 & 2597.022 & PRUGAM \\
\hline 13 & 29 & 511129.526 & 1102329.952 & 2929.902 & PRUGAM \\
\hline 14 & 23 & 515319.164 & 1102602.054 & 3405.798 & PRUGAM \\
\hline 15 & 85 & 513338.232 & 1084848.913 & 1094.927 & PRUGAM \\
\hline 16 & 82 & 503554.838 & 1090269.047 & 1386.729 & PRUGAM \\
\hline 17 & 100 & 504030.204 & 1088024.001 & 1385.450 & PRUGAM \\
\hline 18 & 101 & 505861.617 & 1086737.148 & 1383.669 & PRUGAM \\
\hline 19 & 110 & 502140.315 & 1085174.702 & 1943.028 & PRUGAM \\
\hline 20 & 161 & 504699.926 & 1083235.024 & 1842.781 & PRUGAM \\
\hline 21 & 126 & 498700.221 & 1084064.117 & 1957.697 & PRUGAM \\
\hline 22 & 125 & 495353.716 & 1088254.335 & 1496.965 & PRUGAM \\
\hline 23 & 205 & 497076.230 & 1085542.267 & 1887.769 & PRUGAM \\
\hline 24 & 3 & 510120.563 & 1089621.475 & 1399.049 & ITCR \\
\hline 25 & 4 & 509937.563 & 1091249.816 & 1449.497 & ITCR \\
\hline 26 & 5 & 509509.198 & 1090821.523 & 1432.562 & ITCR \\
\hline 27 & 7 & 508978.591 & 1092470.646 & 1538.441 & ITCR \\
\hline 28 & 8 & 508759.606 & 1090706.695 & 1437.481 & ITCR \\
\hline 29 & 9 & 509965.555 & 1086728.290 & 1315.462 & ITCR \\
\hline 30 & 10 & 506843.771 & 1093300.928 & 1519.391 & ITCR \\
\hline 31 & 11 & 506809.174 & 1088484.997 & 1380.132 & ITCR \\
\hline 32 & 12 & 501174.191 & 1088333.698 & 1413.366 & ITCR \\
\hline 33 & 13 & 513185.474 & 1093449.078 & 1792.631 & ITCR \\
\hline 34 & 14 & 512484.289 & 1095988.101 & 2095.109 & ITCR \\
\hline 35 & 15 & 515278.460 & 1100265.196 & 2875.491 & ITCR \\
\hline 36 & 16 & 512861.754 & 1098278.651 & 2339.675 & ITCR \\
\hline 37 & 17 & 516035.115 & 1103158.253 & 3431.927 & ITCR \\
\hline 38 & 18 & 516892.845 & 1103215.134 & 3349.668 & ITCR \\
\hline 39 & 19 & 517019.404 & 1103342.340 & 3327.381 & ITCR \\
\hline 40 & 20 & 513657.226 & 1088028.895 & 1347.415 & ITCR \\
\hline 41 & 21 & 514725.100 & 1087853.764 & 1326.646 & ITCR \\
\hline 42 & 22 & 514517.700 & 1084449.838 & 1055.068 & ITCR \\
\hline
\end{tabular}


se encarga de definir cuantos puntos de amarre (Tie Points o TPs por sus siglas en inglés) sean necesarios. El resultado de la $A A D$ es una orientación exterior para cada imagen en una localización $X, Y$ y $Z$ (Leica Geosystems, 2010).

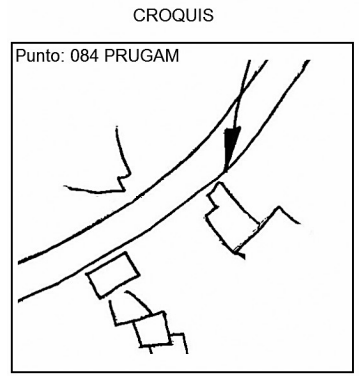

CROQUIS

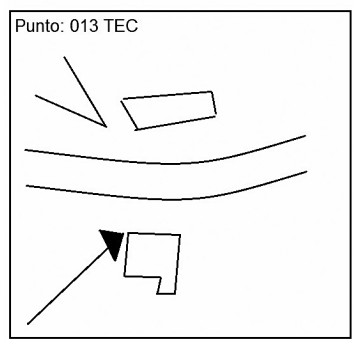

POSICION

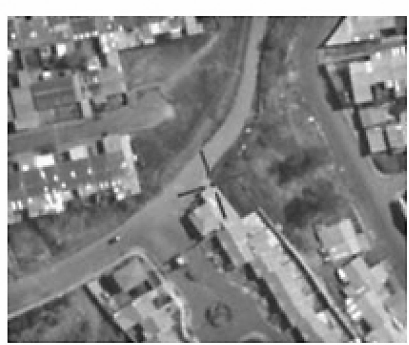

POSICION

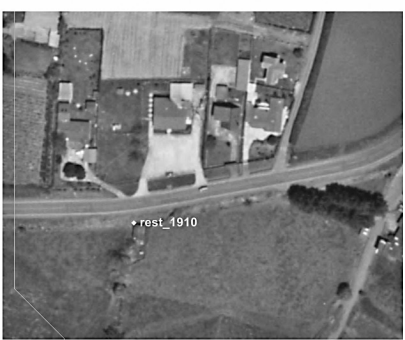

Figura 2. Ubicación externa de dos GCP para las imágenes CARTA-2005.
ERDAS-LPS utiliza una estructura de pirámides para cada imagen. Estas pirámides constituyen archivos de minificación previamente generados con aproximadamente cinco niveles de proceso con diferente resolución. Esta estructura de pirámides se utiliza para iniciar la correlación espacial, partiendo de la más baja hasta mejorar el detalle en la imagen de más alta resolución. Un mínimo de tres puntos es comparado y emparejado por cada posición en la distribución de Grueber.

Finalmente, se ejecutó un ajuste en bloque utilizando ERDAS-LPS para calcular las coordenadas para cada punto de amarre (TP) y determinar con precisión los parámetros de la orientación externa para cada imagen. Los parámetros de la orientación externa fueron utilizados en la orientación de los estéreo modelos y se usan igualmente como datos de entrada en los procesos de ortorectificación y compilación altimétrica.

El ajuste del bloque permitió verificar la calidad de todos los puntos de control utilizados en la AAD. Aquellos con mayor error se ajustaron o eliminaron de acuerdo a la calidad obtenida de la función de costo seleccionada, en este caso el RMSE. La figura 3 muestra la respuesta de la AAD para uno de los bloques armados con las imágenes CARTA-2005, arrojando un RMSEx de 1,54 m y un RMSE y de

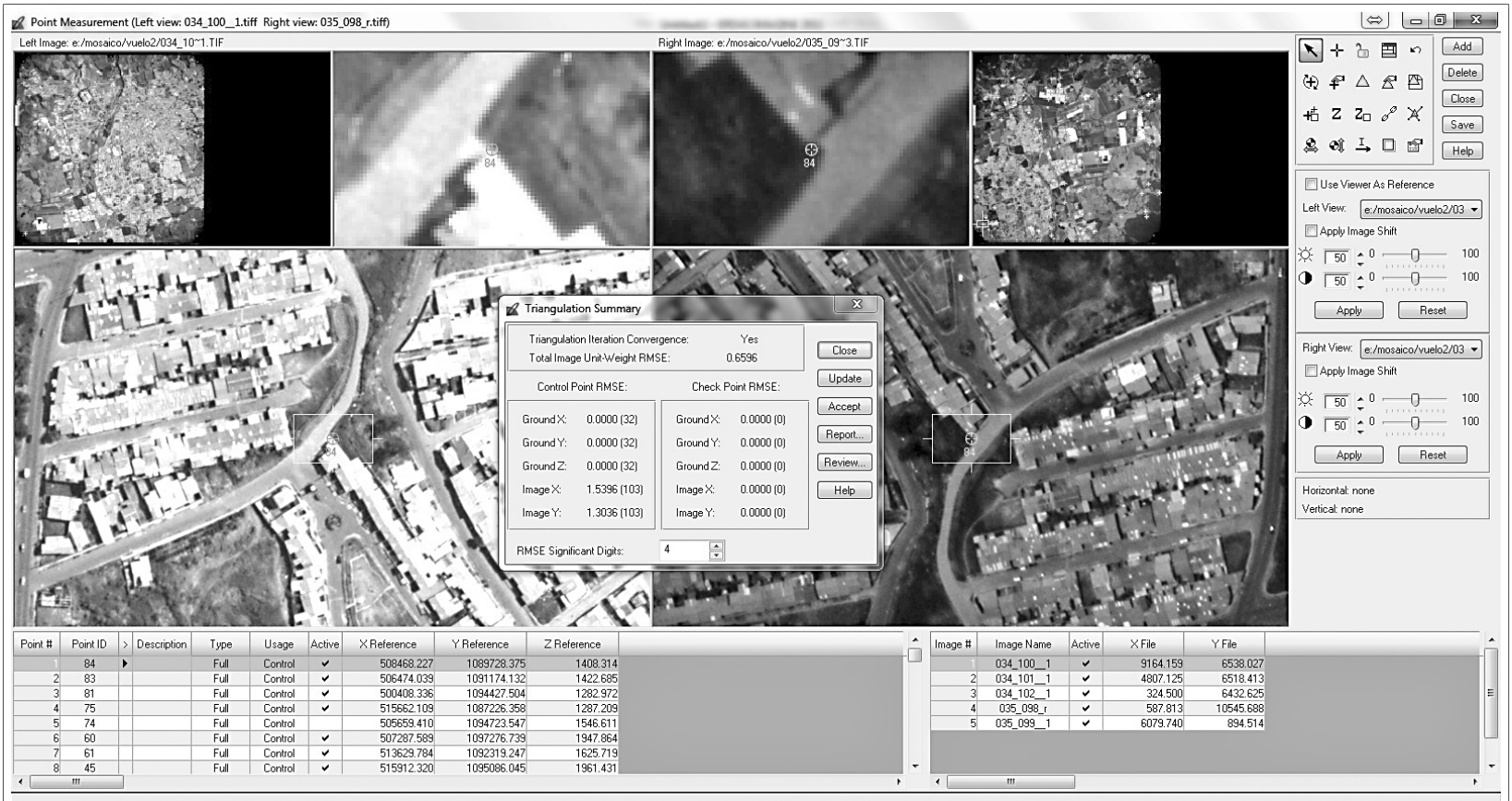

Figura 3. Resultados del ajuste RMSE con base en el proceso AAD ejecutado por ERDAS-LPS. 


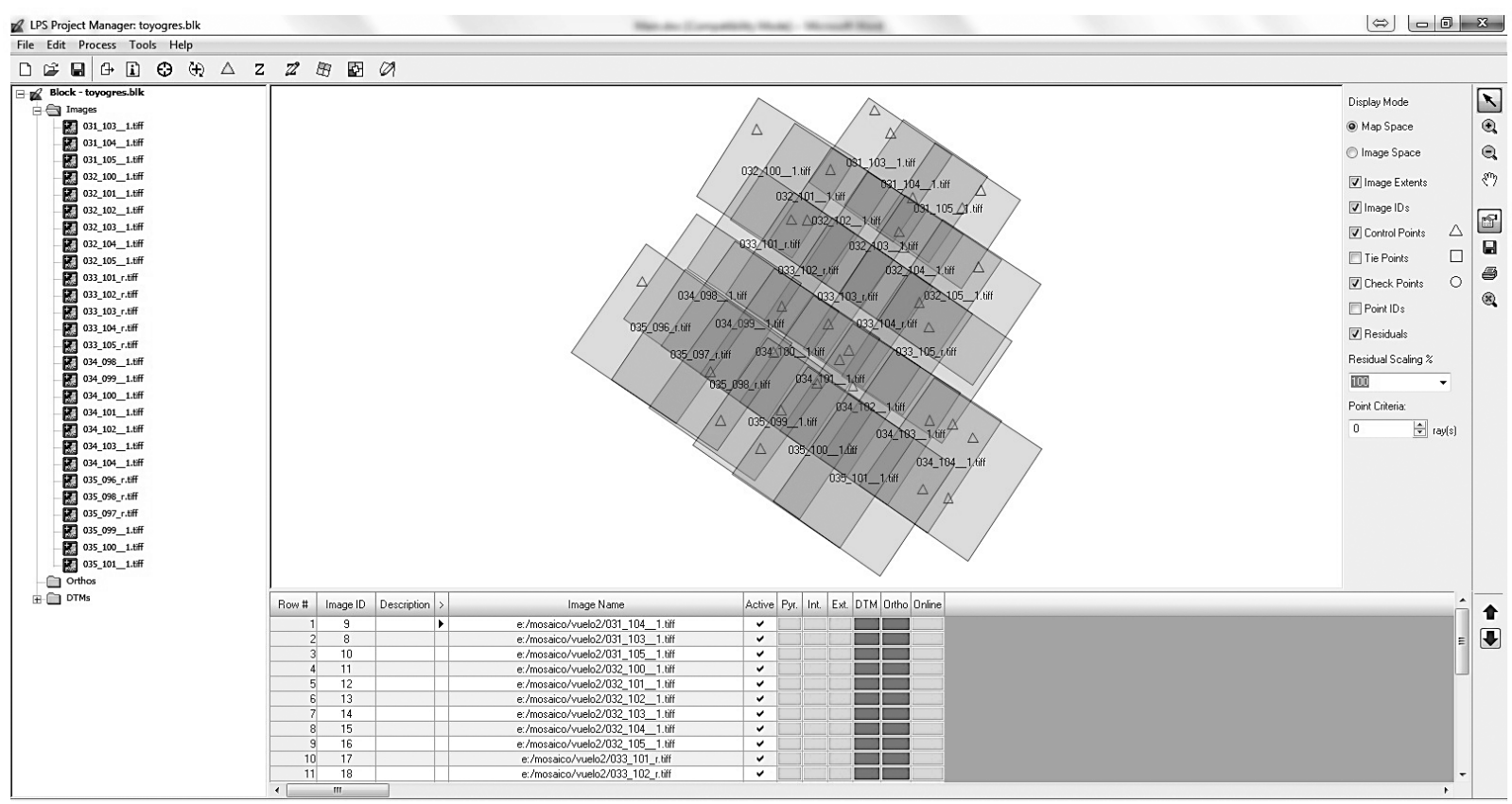

Figura 4. Bloque final de imágenes CARTA-2005 utilizado en el proceso de AAD.

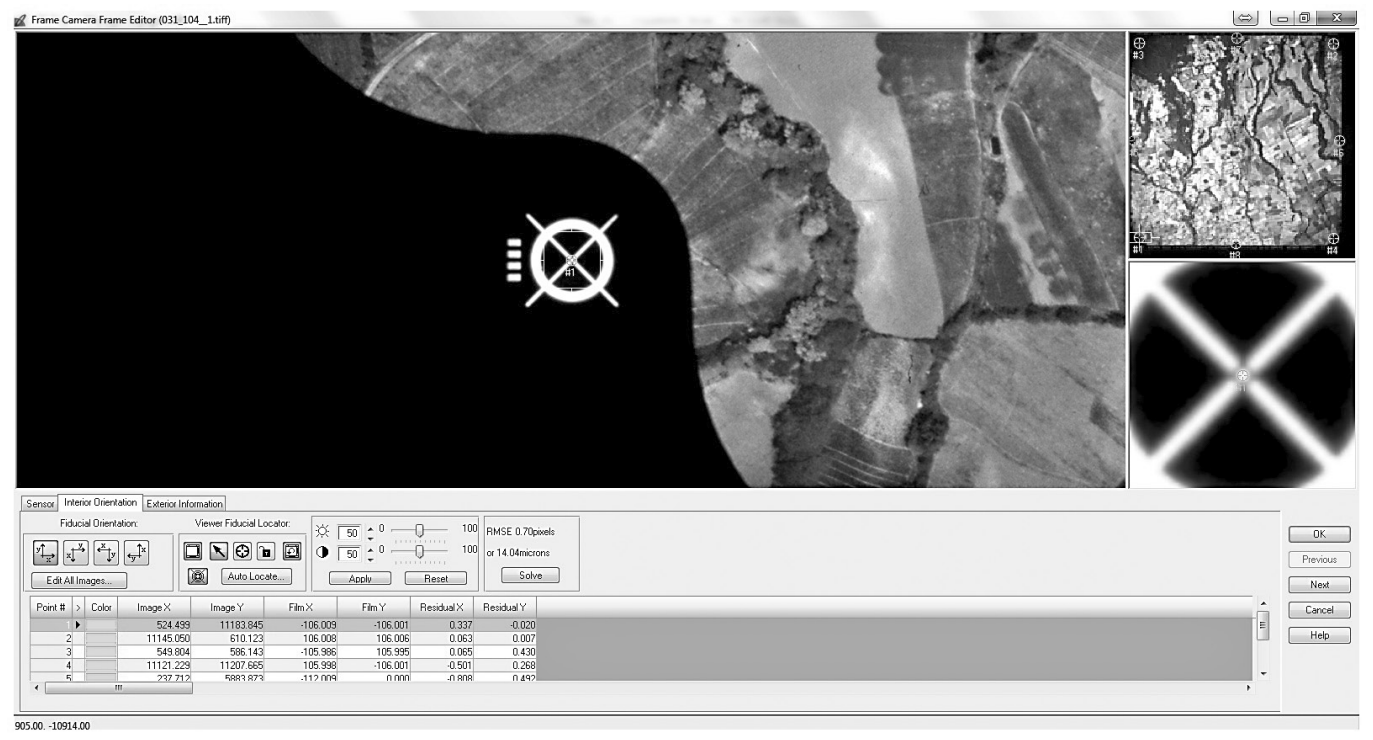

Figura 5. Puntos fiduciales ligados a la orientación interna de una de las imágenes CARTA-2005.

I,30 m para un RSME total (para mayores detalles, ver control de calidad).

\section{Orientación interna}

Se usó un total de 27 fotografías de la misión CARTA-2005 para extraer DEM a partir del proceso ADD para el área en estudio (figura 4). Desde el principio, las fotografías presentaron un sinnúmero de inconformidades que hicieron difícil y lenta su exitosa utilización, tanto en la elaboración de la restitución cartográfica como en la posterior generación de los DEM.

Los problemas de contraste, sombras, baja resolución del escaneo y pérdida de información de estas imágenes hicieron imposible su uso como una composición a color RGB. Por lo tanto, se 


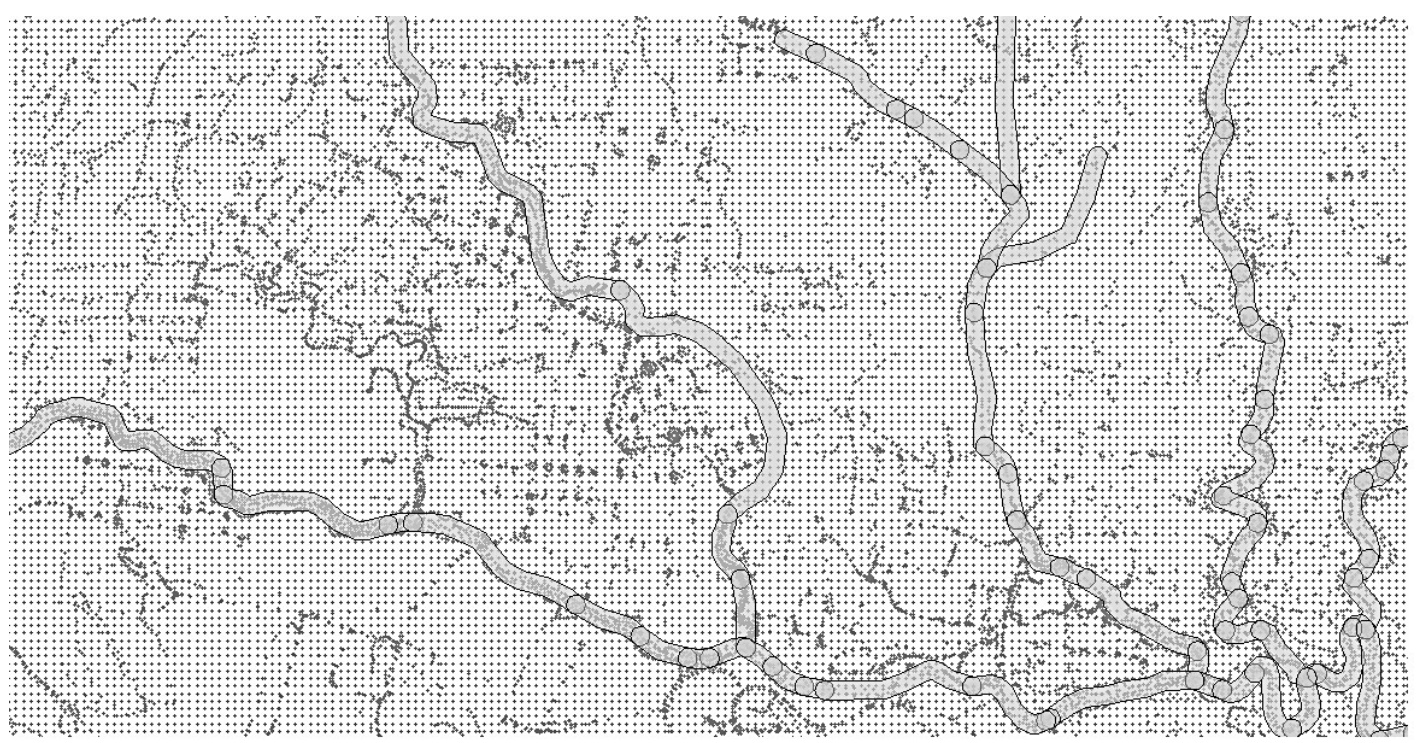

Figura 6. Nube de puntos generada por ERDAS-LPS para la hoja cartográfica Tejar a partir CARTA-2005. Los puntos marcan posiciones $X, Y$ y $Z$, mientras que los polígonos marcan lo que se considera la red de drenaje del área adyacente.

descompusieron en sus respectivas bandas y solo se utilizó la banda roja (que presenta mayor contenido de información) en el proceso AAD.

La cámara que se utilizó en este vuelo fue una Wild-RC30, cuyos parámetros de calibración (incluyendo puntos fiduciales y distancias focales) fueron certificados por el US. Geological Survey. Tales parámetros se incluyeron en ERDAS-LPS para definir la orientación interna de la cámara (figura 5).

\section{Generación de nubes de puntos y curvas de nivel}

Una vez concluidos los procesos de orientación interna, externa y AAD, la ortorectificación de las imágenes arrojó un tamaño de pixel de 1,0 m. Además se generó una red irregular de triángulos (TIN) a partir del DEM para producir una mayor calidad y continuidad en la rectificación de las imágenes. Los parámetros en ERDAS-LPS garantizaron una precisión en RMSExy equivalente a I,5 veces el tamaño de pixel, es decir 1,5 m. Se decidió generar una nube de puntos en ERDAS-LPS para toda el área de estudio (figura 6).

La densidad de puntos para el área correspondiente varió de 456000 a 676 000. Cada uno de estos puntos contiene información precisa en $X, Y$ y $Z$ que luego se usó para generar curvas de nivel a cada 2, 5 y $10 \mathrm{~m}$. Dichas curvas de nivel fueron generadas mediante el SIG SAGA (Böhner et al., 2006) utilizando el proceso de interpolación del inverso del cuadrado de la distancia (Inverse Distance Function o IDF por sus siglas en inglés) con una potencia exponencial de factor 2. Una vez generadas las curvas de nivel, se evaluaron cualitativamente para verificar su integridad. Posteriormente, se implementó un proceso de filtrado para eliminar cúmulos de información que no tuviesen consistencia. En este sentido, aquellas curvas con longitudes menores a $500 \mathrm{~m}$ se eliminaron de la base de datos vectorial.

A partir de las curvas de nivel se generaron DEM con resoluciones de 2,5 y $10 \mathrm{~m}$, utilizando el método de construcción lineal del Borgefors incluido en el SIG ILWIS (ITC 200I). El primer DEM correspondió a aquel con una resolución de $2 \mathrm{~m}$, posteriormente se ejecutó un remuestreo utilizando el algoritmo de vecino más cercano (Nearest Neighbor) para construir los DEM a 5 y 10 m respectivamente. Tales DEM fueron hidroprocesados para su utilización en el modelo SWMM mediante las herramientas de hidroprocesamiento incluidas en el SIG ILWIS. EI objetivo primordial de esta colección de procedimientos es la extracción de la red hidrológica y la determinación del número de subcuencas que integran dos cuencas experimentales de alta pendiente: las del río Toyogres y la quebrada Zopilote (Méndez, 20।2). El diagrama de flujo presentado por la figura 7 resume las actividades realizadas alrededor de las imágenes CARTA-2005 para la producción final de los DEM. 


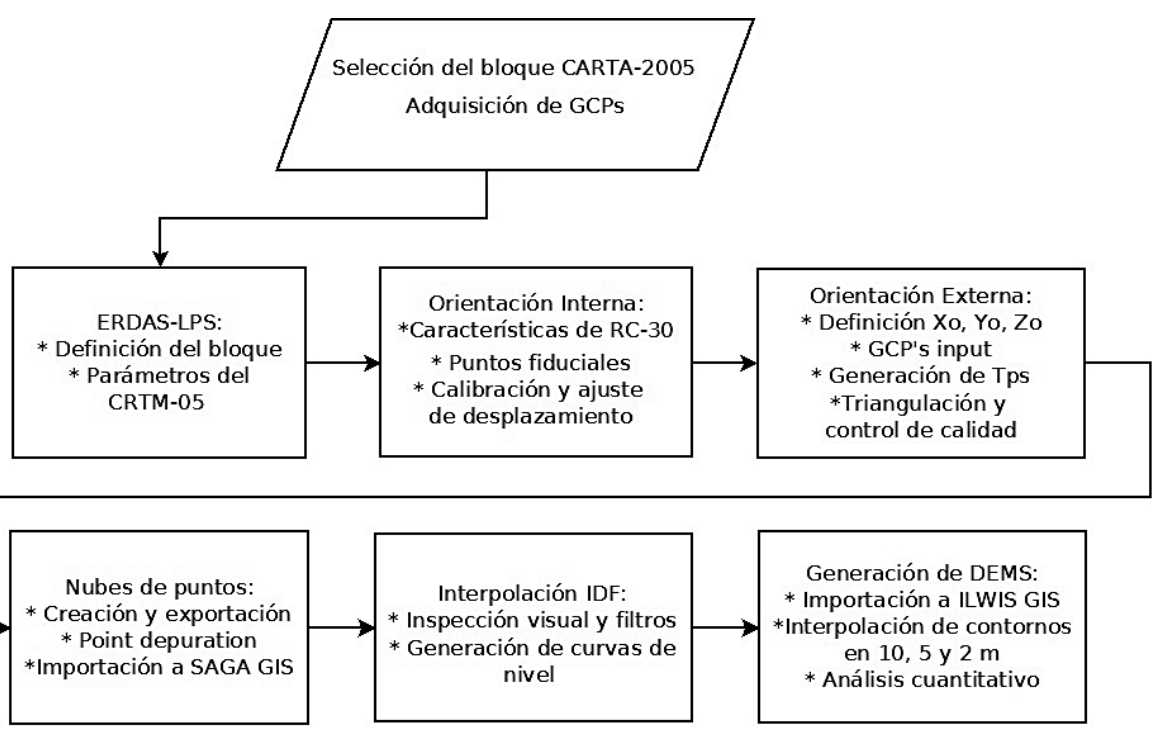

Figura 7. Diagrama de flujo para la generación de DEM.

\section{Control de calidad}

El control de calidad de los DEM se realizó de forma cualitativa, a través de la inspección visual de los contornos generados, y de forma cuantitativa, mediante la aplicación de la función objetivo raíz del error cuadrático medio (RMSE). El RMSE (I) se utilizó para evaluar la desviación entre los GCP (cuadro 2) considerados como observaciones contra los valores de elevación de cada DEM derivado a partir de la nube de puntos generada por ERDAS-LPS.

$\operatorname{RMSE}=\frac{\sum_{\mathrm{i}=1}^{\mathrm{n}}\left(\mathrm{O}_{\mathrm{i}}-\mathrm{M}_{\mathrm{i}}\right)^{2}}{\mathrm{n}}$

Donde: $\mathrm{n}$ se refiere al número total de observaciones, [-]; Oi es el valor observado en el intervalo i, [-]; y Mi es el valor modelado en el intervalo i, [-].

\section{Resultados y análisis}

La figura 8 muestra una comparación cualitativa entre curvas de nivel a cada $50 \mathrm{~m}$ para las fotografías CARTA-2005 antes (figura 8B) y después (figura $8 A$ ) de los procesos de filtrado vectorial. El intervalo de 50 m únicamente tiene propósitos ilustrativos. En apariencia, existe una buena coincidencia entre los sets de curvas para las zonas montañosas y áreas de mayor elevación en el norte de la zona estudio por arriba de los 2000 metros sobre el nivel del mar (msnm).

No obstante, conforme los contornos descienden a altitudes más cercanas hacia las zonas urbanas (por debajo de los 1500 msnm), los datos sin filtrar exhiben un comportamiento errático, con áreas de alta densidad de depresiones en terreno (marcadas en círculos en la figura 8B). Estos cúmulos o clusters son de naturaleza aparentemente artificial y están
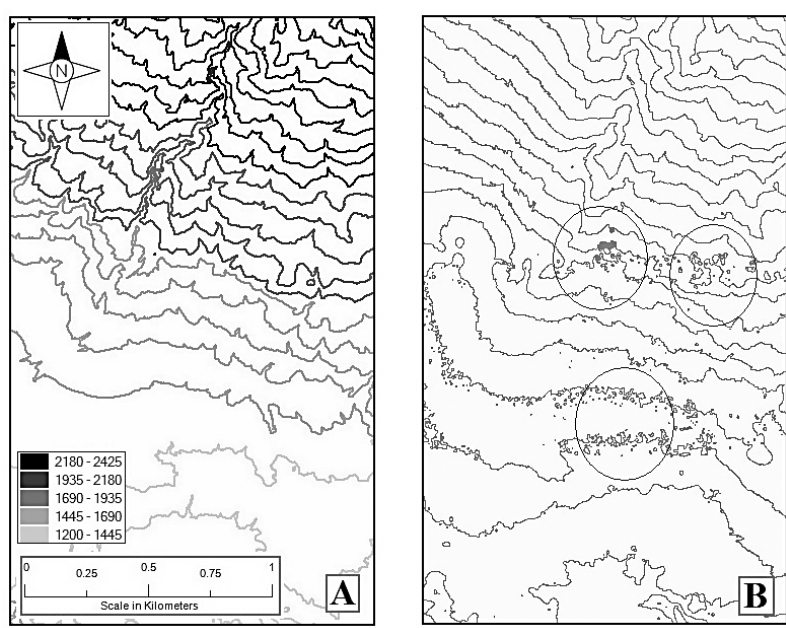

Figura 8. Comparación cualitativa entre curvas de nivel cada $50 \mathrm{~m}$ para las fotografías CARTA2005. 
relacionados propiamente con la calidad de las imágenes utilizadas.

A partir de la primera revisión de los vuelos fotogramétricos entregados por PRUGAM en relación al CARTA-2005, se tomó conciencia de las graves diferencias radiométricas existentes entre las fotografías del vuelo en cuestión. Esto motivó la necesidad de modificar metodologías y procedimientos previos, con el fin de conseguir los resultados esperados a partir del material de entrada. Lo anterior incluyó la extracción de las bandas roja, azul y verde de cada fotografía aérea y su posterior compensación radiológica. En general, fue imposible aplicar la técnica de correlación automática de puntos de paso, puesto que las diferencias radiométricas entre imágenes eran tales que no existía correlación entre las matrices de búsqueda. En los casos más extremos, se dificultaba incluso la identificación manual de puntos homólogos en las imágenes contiguas. Se sospecha que buena parte de las deficiencias mostradas por estas imágenes están principalmente relacionadas con el proceso de escaneo o digitalización de las imágenes análogas originales tomadas con la cámara RC-30. Dicho proceso de digitalización fue dirigido y ejecutado en el CENAT. Desafortunadamente, los negativos originales de tales fotografías no estaban disponibles al momento en que se consultó al CENAT.
Wilkie (1990), Baltsavias \& Stallmann (1993) y Cuartero et al. (2005) discuten ampliamente los problemas asociados a la aerotriangulación de imágenes adquiridas a partir de vuelos aéreos, destacando la dificultad de ubicar GCP en imágenes estéreo, la existencia de diferencias radiológicas entre las imágenes, debido a la toma de datos en diferentes fechas y a diferentes horas del día con diferente grado de iluminación e incidencia solar. Lo anterior contrasta con lo establecido por Subramanian (2003), en su estudio comparativo de varias fuentes de información (aérea y satelital) para la creación de DEM. Uno de los problemas ligados a la orientación interna de las imágenes CARTA-2005 tiene que ver con el certificado de calibración original de la cámara RC-30, que de acuerdo con BLOM (PRUGAM, 2008) parece no corresponder a la supuestamente utilizada en el vuelo. La figura 9A muestra parte del DEM con resolución espacial a 2 m generado para el área de estudio. Se observa que luego del proceso de filtrado vectorial (figura 9B), buena parte de la infraestructura existente puede ser apreciada (véase, por ejemplo, el cañón del río reventado y los diques de protección de la ciudad de Cartago, figura 9C). Desde el punto de vista cuantitativo, el cuadro 3 muestra las cifras relacionadas al RMSE en los DEM generados a partir de las fotografías CARTA-2005 para las resoluciones de 10, 5 y $2 \mathrm{~m}$ respectivamente.
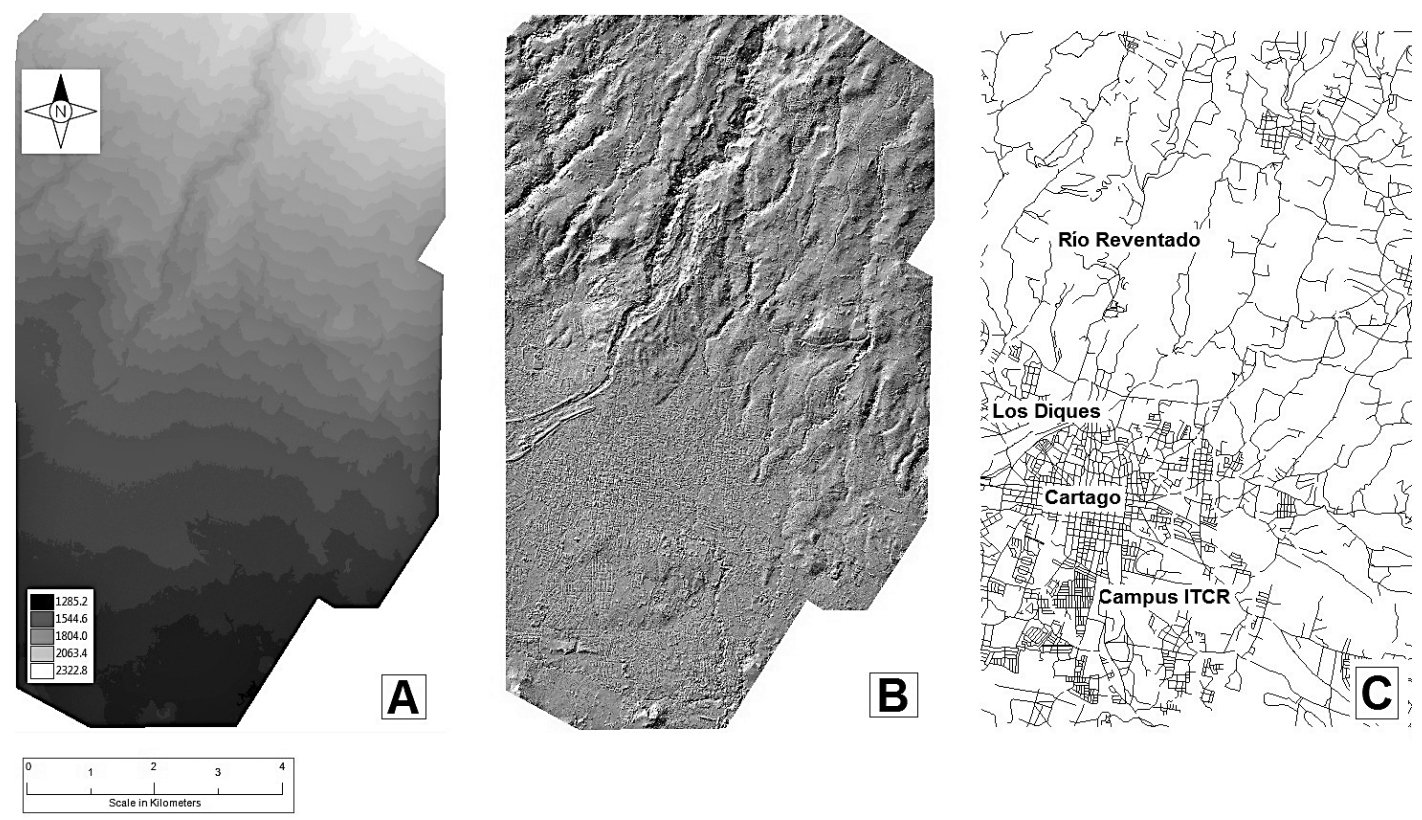

Figura 9. Representaciones del DEM resultante con resolución de 2 m. 
Cuadro 3. Control de calidad de los DEM generados a partir de las fotografías CARTA2005..

\begin{tabular}{|c|c|c|}
\hline Resolución DEM $(m)$ & RMSE $(m)$ & GCP \\
\hline 2 & 0,809 & 18 \\
\hline 5 & 1,121 & 18 \\
\hline 10 & 1,378 & 18 \\
\hline
\end{tabular}

Puede notarse que para todas las resoluciones probadas, el RMSE está por debajo del umbral de I,5 m originalmente adoptado para evaluar la precisión de la elevación en la vertical, por lo que todos los DEM se consideran aptos para su postprocesamiento en ILWIS.

\section{Conclusiones}

Se utilizaron las fotografías aéreas CARTA-2005 para la generación de Modelos de Elevación Digital (DEM) en varias resoluciones espaciales para un área de estudio ubicada en Cartago, Costa Rica. Dichas fotografías presentan diversas deficiencias que hacen difícil su utilización en procesos de Aerotriangulación Analítica Digital (AAD). El mayor de los problemas tiene que ver con la calidad del proceso de escaneo digital de las fotografías análogas originales.

Aun así, mediante diversos procesos de compensación radiológica, filtrado vectorial y amparándose en una densa red de control de puntos de control en tierra (GCP), fue posible generar DEM que cumplen con los criterios de aceptación cuantitativos ligados a la función objetivo RMSE.

Se recomienda utilizar estos productos con sumo cuidado y de ser posible reescanear las imágenes análogas del vuelo original. Es deseable la comparación de estos productos versus aquellos generados con imágenes satelitales de alta resolución. Aun así, el vuelo CARTA-2005 representa una fuente valiosa de información del territorio costarricense.

\section{Bibliografía}

Baltsavias P. \& Stallmann D. (1993). SPOT Stereo matching for Digital Terrain Model generation. Zürich, 2nd Swiss Symposium on Pattern Recognition and Computer.

Böhner, J., McCloy, K.R. \& Strobl, J. (2006). SAGA Analysis and Modelling Applications. Göttinger Geographische Abhandlungen Vol. I I 5, I30 pp.

Brockerhoff, M.P. (2000). An urbanizing world. Pop. Bull. 55, 3-44.

Cuartero, A., Felicísimo, A.M. \& Ariza, F.J. (2004). Accuracy of DEM Generation from Terra-aster Stereo Data. Istanbul, $X X$ th ISPRS Congress. Geo-Imagery Bridging Continents.

Hunter, N.M., Bates, P.D., Horritt, M.S. \& Wilson, M.D. (2007). Simple spatially-distributed models for predicting flood inundation: A review. Geomorphology 90: 208-225.

IGN (Instituto Geográfico Nacional de Costa Rica). (2008). Sistema de Referencia CR05 y Proyección Transversal Mercator para Costa Rica CRTM05. Unidad Ejecutora, Programa de Regularización de Catastro y Registro.

ITC. (200I). ILWIS 3.0 Academic User's Guide. International Institute for Aerospace Survey and Earth Sciences (ITC). Enschede, The Netherlands.

Leica Geosystems. (20 I0). ERDAS field guide. Norcross, Georgia: Leica Geosystems Geospatial Imaging, LLC.

Méndez, M. (en prensa). Calibración y validación del modelo hidrológico SWMM en cuencas hidrológicas de alta pendiente. Tecnología en Marcha.

Miller, R. \& Small, C. (2003). Cities from space: potential applications of remote sensing in urban environmental research and policy. Environmental Science \& Policy 6: 129-137.

PRUGAM (2008). Planificación regional y urbana de la Gran Área Metropolitana (GAM) del Valle Central de Costa Rica. Estudio sobre Base Territorial y Zonificación Ambiental para la GAM (Proyecto I-O-0205-06-IT-PRUGAM). Informe final.

Subramanian, K.S., Singh, A. \& Sudhakar, M. (2003). Evaluation of Digital Elevation Models created from different satellite images. Map India in Technology.

Wilkie, D.S. (1990). GPS Location Data:An Aid to Satellite Image Analyses of Poorly Mapped Regions. International Journal of Remote Sensing I I (4): 653-658.

Wu, S., Li, L. \& Huang, G.H. 2008. A study on DEM-derived primary topographic attributes for hydrologic applications: Sensitivity to elevation data resolution. Applied Geography 28: $210-223$. 